\title{
Transcriptome profiling of Fagopyrum tataricum leaves in response to lead stress
}

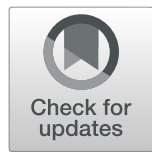

Lei Wang, Bei Zheng, Yong Yuan, Quanle Xu* and Peng Chen ${ }^{*}$

\begin{abstract}
Background: Lead (Pb) pollution is a widespread environmental problem that is harmful to living organisms. Tartary buckwheat (Fagopyrum tataricum), a member of the family Polygonaceae, exhibits short growth cycles and abundant biomass production, could be an ideal plant for phytoremediation due to its high Pb tolerance. Here, we aimed to explore the molecular basis underlying the responses of this plant to Pb stress.

Results: In our study, ultrastructural localization assays revealed that Pb ions primarily accumulate in leaf vacuoles. RNA deep sequencing (RNA-Seq) of tartary buckwheat leaves was performed on two Pb-treated samples, named $\mathrm{Pb} 1\left(2000 \mathrm{mg} / \mathrm{kg} \mathrm{Pb}\left(\mathrm{NO}_{3}\right)_{2}\right)$ and Pb2 $\left(10,000 \mathrm{mg} / \mathrm{kg} \mathrm{Pb}\left(\mathrm{NO}_{3}\right)_{2}\right)$, and a control (CK). A total of 88,977 assembled unigenes with 125,203,555 bases were obtained. In total, 2400 up-regulated and 3413 down-regulated differentially expressed genes (DEGs) were identified between CK and Pb1, and 2948 up-regulated DEGs and 3834 downregulated DEGs were generated between $\mathrm{CK}$ and Pb2, respectively. Gene Ontology (GO) and pathway enrichment analyses showed that these DEGs were primarily associated with 'cell wall', 'binding', 'transport', and 'lipid and energy' metabolism. The results of quantitative real-time PCR (qRT-PCR) analyses of 15 randomly selected candidate DEGs and 6 regulated genes were consistent with the results of the transcriptome analysis. Heterologous expression assays in the yeast strain $\Delta y c f 1$ indicated that overexpressing CCCH-type zinc finger protein 14 (ZFP14) enhanced sensitivity to $\mathrm{Pb}^{2+}$, while 5 other genes, namely, metal transporter protein C2 (MTPC2), phytochelatin synthetase-like family protein (PCSL), vacuolar cation/proton exchanger 1a (VCE1a), natural resistance-associated macrophage protein 3 (Nramp3), and phytochelatin synthetase (PCS), enhanced the Pb tolerance of the mutant strain.

Conclusion: Combining our findings with those of previous studies, we generated a schematic model that shows the metabolic processes of tartary buckwheat under Pb stress. This study provides important data for further genomic analyses of the biological and molecular mechanisms of $\mathrm{Pb}$ tolerance and accumulation in tartary buckwheat.
\end{abstract}

Keywords: Fagopyrum tataricum, Lead stress, Transcriptome, Ultrastructural localization, Heterologous expression

\section{Background}

Lead $(\mathrm{Pb})$ is one of the most toxic inorganic metal pollutants worldwide and is a persistent environmental contaminant. $\mathrm{Pb}$ is generated by many industrial processes and is subsequently discharged into soils, waters and the atmosphere, potentially inducing a broad range of toxic effects in living organisms [1-4]. As one of the non-essential ions, Pb toxicity in plants results in seed germination inhibition, restrained growth of seedings, wither, and crop yield reduction

* Correspondence: xuq103@163.com; pengchen@nwsuaf.edu.cn Department of Biochemistry \& Molecular Biology, College of Life Sciences, Northwest A\&F University, Yangling 712100, Shaanxi, China
[5]. It penetrates plants through the roots and is transported to shoot tissues [6,7], causing a number of toxic effects on plant morphology, including enzymatic reactions, chlorophyll biosynthesis, membrane permeability and a number of other metabolic processes $[5,8,9]$. Therefore, plants can serve as effective biological monitors and indicators for environmental quality assessments $[10,11]$. Meanwhile, phytoremediation has been considered to be an inexpensive remediation technology to remove heavy metals from contaminated soils [12].

Currently, a number of plant species have been studied to understand the mechanism of $\mathrm{Pb}$ tolerance and

(C) The Author(s). 2020 Open Access This article is distributed under the terms of the Creative Commons Attribution 4.0 International License (http://creativecommons.org/licenses/by/4.0/), which permits unrestricted use, distribution, and 
phytoremediation, but differ with species in $\mathrm{Pb}$ uptake, transportation, accumulation and tolerance [13]. In this connection, Ferreyroa et al. [14] have characterized Brassica napus plant's performance for metal accumulation and detoxification mechanism, and the results suggest a decrease in chlorophyll contents at low $\mathrm{Pb}$ concentration and cell damage at higher lead concentration. Additionally, Acalypha indica plant has been observed to show the physiological and biochemical changes under exposure to lead (100-500 $\mathrm{mg} \mathrm{L}^{-1}$ ) [15], but only grows in the tropics with a narrower adaptable. In a study, Platanus acerifolia has been demonstrated the molecular regulation mechanism of $\mathrm{Pb}$ accumulation and tolerance with $12 \mathrm{~g} \mathrm{~L}^{-1} \mathrm{~Pb}\left(\mathrm{NO}_{3}\right)_{2}$, and considered to be well adapt to $\mathrm{Pb}$ pollution [16]. However, it is a perennial woody plant which needs to take years to purify the soil. Thus, the phytoremediation was restricted by the lack of $\mathrm{Pb}$ hyperaccumulators, relatively low biomass and poor adaptation ability.

Tartary buckwheat (Fagopyrum tataricum) belongs to the eudicot family Polygonaceae [17] that has been widely domesticated as a food and ornamental crop in some East Asian countries [18, 19]. Buckwheat is widely adaptable to low-fertility soils, exhibiting high biomass accumulation and short growth cycles [20]; additionally, it was showed that buckwheat accumulates more $\mathrm{Pb}$ in its shoots and especially in its leaves. Moreover, buckwheat accumulates lead without displaying symptoms of growth inhibition [21]. In a comparison of three different cultivars of buckwheat (Xiqiao No. 1, Jinqiao No. 1, and Jiujiang) treated with $\mathrm{Pb}^{2+}$, Jiujiang displayed few or no toxicity symptoms and exhibited fewer changes in relative cytoplasmic membrane permeability and chlorophyll content than the other assayed cultivars [22]. Tartary buckwheat has been reported to be rich in flavonoids and phenols [23], molecules that protect plants from the adverse effects of active free radicals resulting from $\mathrm{Pb}$-induced oxidative stress [24]. Consequently, tartary buckwheat can be used as potential accumulator species for remediation of $\mathrm{Pb}$ contaminated environment. However, none of the genes and metabolic pathways involved in regulating the $\mathrm{Pb}$ stress response in tartary buckwheat have been identified, interfering our understanding of $\mathrm{Pb}$ tolerance mechanisms in this important accumulator crop.

Next-generation sequencing (NGS) techniques are become powerful tools for life science research and have promoted the rapid discovery of previously unknown genes. For example, RNA deep sequencing (RNA-Seq) has been used in molecular studies of the environmental stress responses of many plants. Wu et al. [25] reported the salt-responsive transcriptome of Fagopyrum tataricum and identified 455 DEGs involved in the salt stress response. It is an effective approach for data mining of a species whose genome database was not available. With respect to $\mathrm{Pb}$ toxicity, Tian et al. [26] analysed the transcriptome of Louisiana iris root and identified many important candidate genes and pathways in order to discover the mechanism related to the lead tolerance and accumulation. In maize, a number of transcription factor (TF) families that response to $\mathrm{Pb}$ exposure, including bZIP, ERF and GARP, were upregulate under $\mathrm{Pb}$ stress in the roots [27]. Moreover, the study demonstrated that several genes involved in the ABA biosynthetic pathway were upregulated in the roots and shoots of Hirschfeldia incana after treatment with $\mathrm{Pb}$, suggesting that ABA-mediated signalling is potentially involved in the response of this plant to lead [28]. In addition, RNA-Seq analyses of the Platanus acerifolia have identified 16,246 DEGs associated with $\mathrm{Pb}$ exposure, including antioxidant enzymes, metal transporters and chelate proteins [16]. These results indicate that the regulatory network and defence system are complex and unique specificities in different plants under $\mathrm{Pb}$ stress.

Although tartary buckwheat has previously been characterized with respect to $\mathrm{Pb}$ tolerance and accumulation [22], as described above, the corresponding molecular mechanisms have not been deciphered. For example, the regulated gene responsible for $\mathrm{Pb}$-induced protection has not been identified. When $\mathrm{Pb}$ is transported from soil to the vacuoles of leaves, the process involves multiple metabolic pathways; however, none of these pathways has been elucidated in buckwheat thus far. In the present study, we determined that the leaf is the main storage tissue by comparing the ultrastructural localization of $\mathrm{Pb}$ in different tissues. Then we used Illumina sequencing technology to gain a highquality genome-wide transcript of tartary buckwheat leaves under $\mathrm{Pb}$ exposure and to identify crucial genes and pathways that are involved in tolerance mechanisms for this heavy metal, with the goal of applying this information to phytoremediation.

\section{Results \\ Concentration and subcellular distribution of $\mathrm{Pb}$ in different tissues of tartary buckwheat}

Lead exposure up to $10,000 \mathrm{mg} / \mathrm{kg}$ reduced height but had no other effect on the buckwheat plants (Fig. 1a, b); this was the highest concentration assayed in subsequent experiments. Furthermore, lead exposure caused no change in MDA content, GSH content, soluble protein and SOD activity indicating the treatments did not cause damage to the leaf physiology (Additional file 1: Figure $\mathrm{S} 1)$. Subsequently, the $\mathrm{Pb}$ content in different tissues was analysed (Fig. 1c), and the Pb content in the roots progressively increased when the $\mathrm{Pb}$ concentration exceeded $5000 \mathrm{mg} / \mathrm{kg}$ soil. In contrast, the $\mathrm{Pb}$ content in the leaves increased progressively at $\mathrm{Pb}$ concentrations ranging from 1000 to $10,000 \mathrm{mg} / \mathrm{kg}$ soil. 

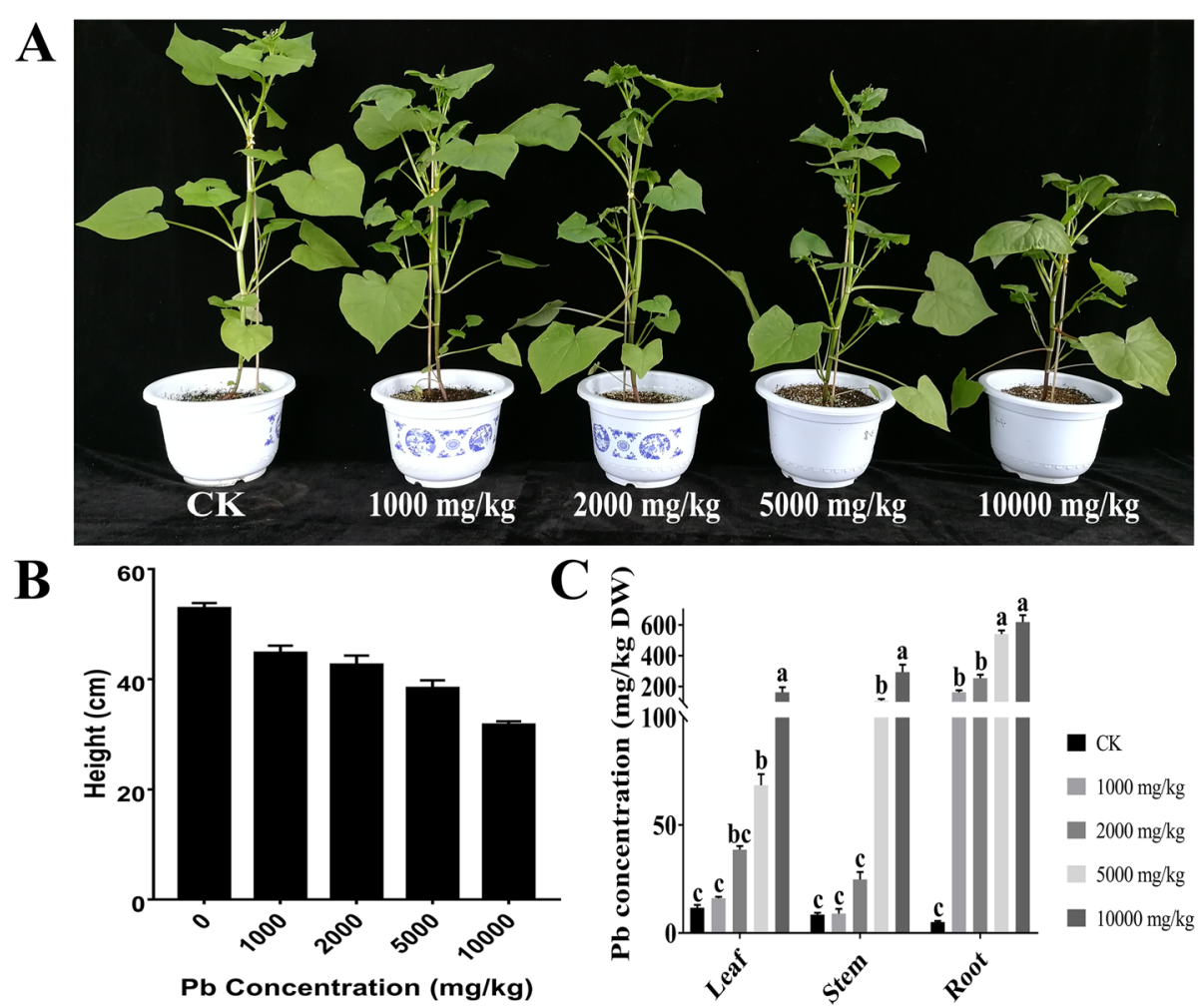

Fig. 1 The response of $F$. tataricum to lead treatment. a The phenotype of $F$. tataricum growth on medium with different $\mathrm{Pb}$ concentrations. $\mathbf{b}$ The height of $F$. tataricum growth on medium with different Pb concentration. Plants were treated with 0, 1000, 2000, 5000, or 10,000 mg/kg Pb $\left(\mathrm{NO}_{3}\right)_{2}$ for 30 days. $\mathbf{c}$ The Pb contents in the leaves, stems and roots of $\mathrm{F}$. tataricum were determined by atomic absorption spectrophotometry (AAS). The data are presented as the mean \pm SE $(n=3)$. Bars with different lowercase letters are significantly different at $P<0.05$ (Tukey's test)

The results of transmission electron microscopy (TEM) analyses revealed that $\mathrm{Pb}$ ions were primarily distributed within the vacuoles and walls of leaf cells, with fewer ions observed in the intercellular spaces (Fig. 2d). In parts of stem cells, some $\mathrm{Pb}$ ions were observed in vacuoles (Fig. 2e), whereas in the roots, $\mathrm{Pb}$ ions were primarily deposited in the cell walls and intercellular spaces
(Fig. 2f). Based on these results, we chose to use leaves in subsequent experiments.

\section{De novo assembly and annotation}

To identify genes associated with $\mathrm{Pb}$ tolerance and accumulation in the leaves of tartary buckwheat, three biological replicates each were selected from the non-treated,

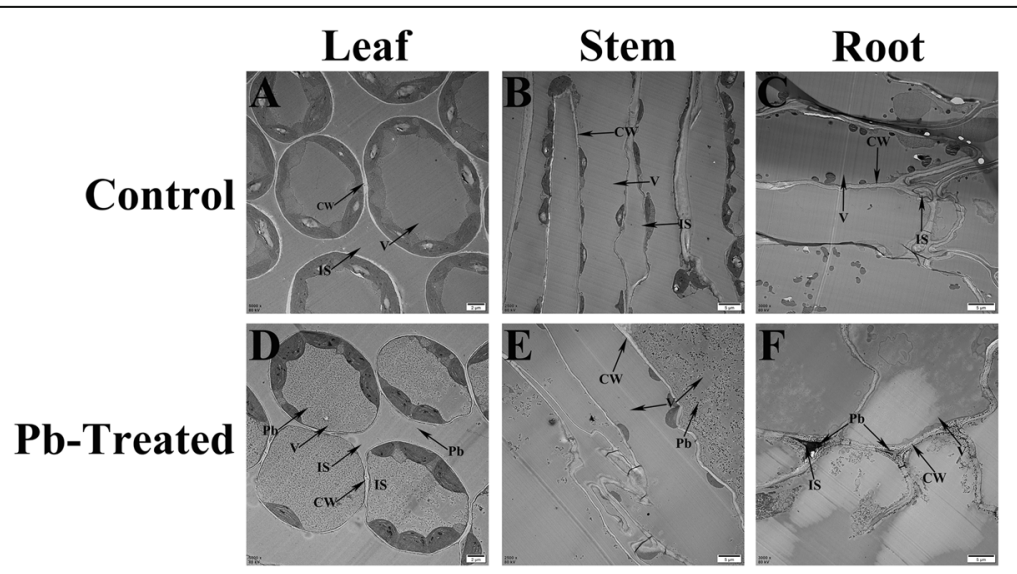

Fig. 2 Ultrastructure of F. tataricum and Pb localization under the 10,000 mg/kg Pb treatment. A control leaf (a), stem (b) and root (c) compared to a Pb-treated leaf (d), stem (e) and root (f). IS, intercellular space; V, vacuole; CW, cell wall. (A, D, Bar $=2 \mu m ; B, C, E, F, B a r=5 \mu m$ ) 
$2000 \mathrm{mg} / \mathrm{kg} \quad \mathrm{Pb} \quad\left(\mathrm{NO}_{3}\right)_{2}$-treated and $10,000 \mathrm{mg} / \mathrm{kg} \mathrm{Pb}$ $\left(\mathrm{NO}_{3}\right)_{2}$-treated groups for cDNA library construction and transcriptome sequencing by using an Illumina HiSeq 4000 instrument.

An overview of the RNA-Seq reads derived from the sequencing results is presented in Table 1 . For the three group samples, the average Q20 and GC content values of these clean reads were greater than 96 and $47 \%$, respectively. A total of 88,977 unigenes with 125,203,555 unigene bases, a length range of $201-19,818 \mathrm{bp}$ and an average length of $982.34 \mathrm{bp}$ were assembled using the unigene database (Table 1; Additional file 2: Figure S2). A significant match in at least one of the above databases was obtained for 39 , $321(44.18 \%)$ unigenes (Table 2). Among these unigenes, 27,071 (69\%) unigenes were annotated in function. Regarding the alignment distribution, 18,434 (48.38\%) of the annotated unigenes matched 14 species, and 33,080 (84.14\%) unigenes matched a database sequence with a similarity of 60 to $100 \%$ (Additional file 3: Table S1).

\section{DEGs under $\mathrm{Pb}$ stress}

To identify unigenes that were induced by $\mathrm{Pb}$ stress, the three libraries were divided into two groups $(\mathrm{CK}$ vs $\mathrm{Pb} 1$ and $\mathrm{CK}$ vs $\mathrm{Pb} 2$ ), and 4525 common DEGs (Additional file 4: Figure S3) were identified in these comparisons. In total, we identified 1641 upregulated (Fig. 3a) and 2884 downregulated (Fig. 3b) unigenes under $\mathrm{Pb}$ stress. Among these 4525 DEGs, 3975 (87.84\%) were annotated by the NR database.
Table 2 Statistics for functional annotations

\begin{tabular}{llll}
\hline Database & Total unigenes & Annotated unigenes & Percentage \\
\hline Pfam & 88,977 & 34,945 & $39.27 \%$ \\
KEGG & 88,977 & 26,443 & $29.72 \%$ \\
Swiss-Prot & 88,977 & 37,824 & $42.51 \%$ \\
COG & 88,977 & 8727 & $9.81 \%$ \\
GO & 88,977 & 27,071 & $30.42 \%$ \\
\hline
\end{tabular}

A hypergeometric distribution was used to classify the DEGs into 20 level-2 GO terms (Fig. 3c). In detail, GO enrichment analysis identified 145 molecular function (MF) terms, 244 biological process (BP) terms and 64 cellular component (CC) terms (Additional file 5: Table S2). For these GO terms, significantly overrepresented $(P<0.05)$ terms in the MF category included catalytic 'activity' (GO:0003824), 'binding' (GO:0005488), 'transporter activity' (GO: 0005215), and 'nucleic acid binding transcription factor activity' (GO:0001071). For BP terms, the most significantly overrepresented terms were 'metabolic process' (GO:0008152), 'cellular process' (GO: 0009987), 'single-organism process' (GO:0044699) and 'biological regulation' (GO:0065007). 'Membrane' (GO: 0016020), 'membrane part' (GO:0044425), 'cell' (GO: 0005623), 'cell part' (GO:0044464) and 'organelle' (GO:0043226) were significantly overrepresented terms in the CC category. In summary, the identified unigenes in tartary buckwheat under $\mathrm{Pb}$ stress were primarily associated with catalytic activity, binding, metabolic processes and membrane components.

Table 1 Throughput and quality of strand-specific RNA-seq of F. tataricum libraries

\begin{tabular}{|c|c|c|c|}
\hline & CK & $\mathrm{Pb} 1$ & $\mathrm{~Pb} 2$ \\
\hline \multicolumn{4}{|l|}{ HiSeq Statistics } \\
\hline Raw reads & $48,264,504$ & $51,792,400$ & $47,292,888$ \\
\hline Raw base (bp) & $7,287,940,104$ & $7,820,652,400$ & $7,141,226,088$ \\
\hline$>$ Q20 of raw data (\%) & 97.07 & 97.29 & 96.84 \\
\hline Clean reads & $47,737,814$ & $51,208,144$ & $46,731,827$ \\
\hline Clean base (bp) & $7,126,704,866$ & $7,613,422,269$ & $6,959,839,129$ \\
\hline > Q20 clean reads (\%) & 97.68 & 97.91 & 97.50 \\
\hline GC percentage (\%) & 50.48 & 53.15 & 49.01 \\
\hline \multicolumn{4}{|c|}{ Assembly data (all the clean reads of the 6 libraries were assembled together) } \\
\hline Total unigene number & 88,977 & & \\
\hline Total unigene base & $125,203,555$ & & \\
\hline Percent GC & 41.27 & & \\
\hline Length of the largest unigene (bp) & 19,818 & & \\
\hline Length of the smallest unigene (bp) & 201 & & \\
\hline Average length & 982.34 & & \\
\hline N50 & 1730 & & \\
\hline E90N50 & 1942 & & \\
\hline
\end{tabular}



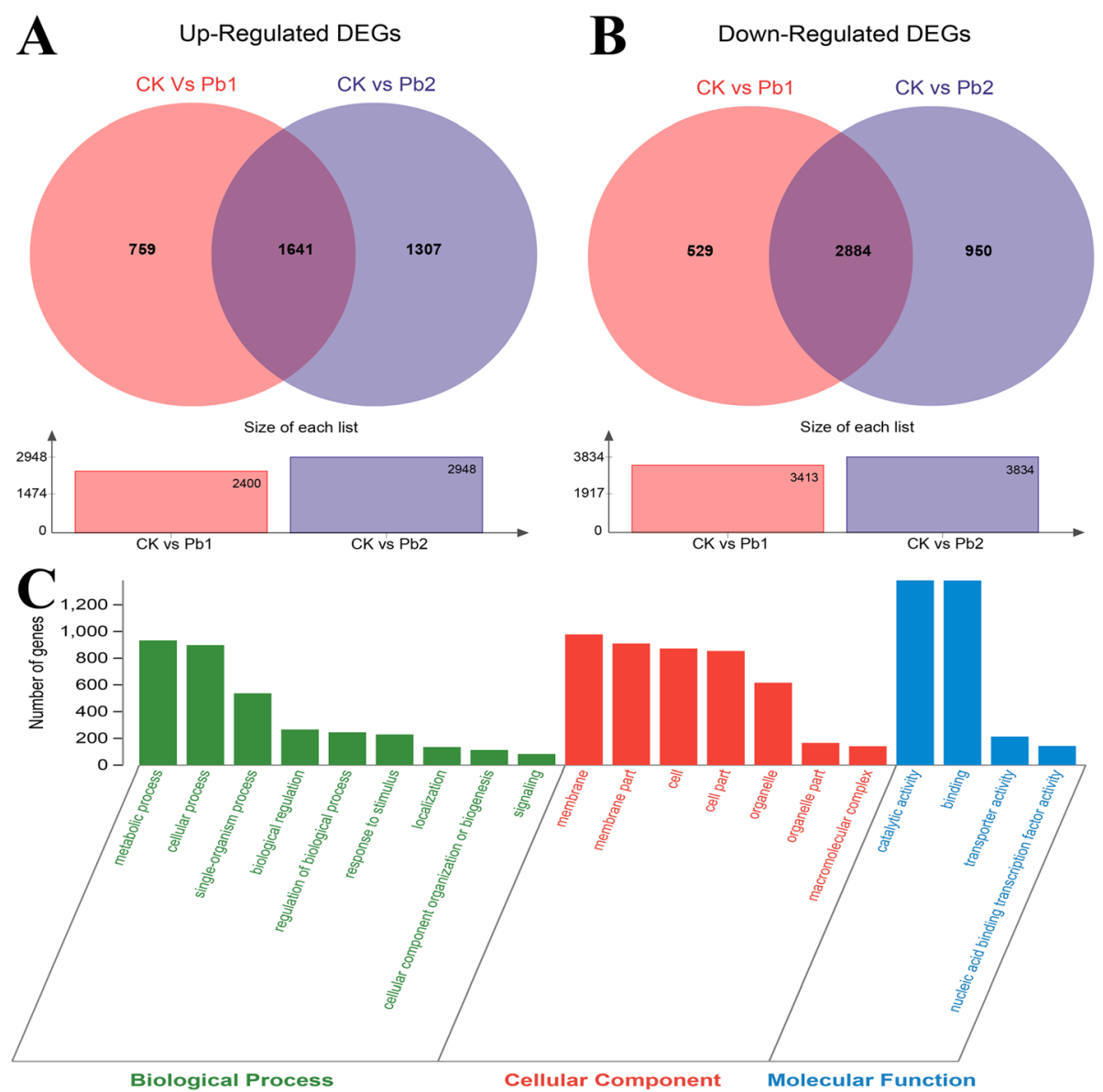

Fig. 3 Venn diagram of differentially expressed genes (DEGs) for CK vs Pb1 and CK vs Pb2 and Gene Ontology classification of DEGs. a) Upregulated DEGs for CK vs Pb1 and CK vs Pb2; (b) Downregulated DEGs for CK vs Pb1 and CK vs Pb2; (c) GO classification of DEGs for CK vs Pb1 and CK vs Pb2. The $x$-axis represents GO terms belonging to three categories; the $y$-axis represents the gene numbers for each term

KEGG pathway enrichment analysis of $\mathrm{CK}$ vs $\mathrm{Pb} 1$ and $\mathrm{CK}$ vs $\mathrm{Pb} 2$ identified 106 enriched pathways (Additional file 6: Table S3), 17 of which were significantly enriched at $P<$ 0.05 under $\mathrm{Pb}$ stress (Table 3). The four most common pathways responding to $\mathrm{Pb}$ stress were 'plant hormone signal transduction' (ko04075, 82), 'plant-pathogen interaction' (ko04626, 56), 'MAPK signalling pathway - plant' (ko04016, 65) and 'phenylpropanoid biosynthesis' (ko00940, 45). These results indicate that $\mathrm{Pb}$ stress in F. tataricum primarily influences pathways associated with energy metabolism, lipid metabolism, secondary metabolites, nonenzymatic antioxidants and oxidative phosphorylation.

\section{Validation and heterologously expression of DEGs}

To confirm the accuracy of the RNA-Seq data, 21 unigenes were selected to investigate their transcriptional expression in the leaves via qRT-PCR. The results showed that the RNA-Seq data were well correlated with the qRT-PCR results (Fig. 4), indicating the reliability of the RNA-seq data.

Moreover, we have particularly analysed 6 unigenes (MTPC2, ZFP14, PCSL, VCE1a, Nramp3, and PCS) which were regulated in response to $\mathrm{Pb}$ stress (Fig. 5a). As results, three upregulated genes (ZFP14, PCS, and VCE1a) were significantly differentially expressed under both assayed concentrations of $\mathrm{Pb}^{2+}$. The increase in ZFP14 expression was the same in the two $\mathrm{Pb}$ stress samples, whereas the increases in PCS and VCE1a expression increased sharply with increasing $\mathrm{Pb}^{2+}$ concentrations. In contrast, MTPC2, PCSL and Nramp3 were not significantly upregulated in the $2000 \mathrm{mg} / \mathrm{kg} \mathrm{Pb}^{2+}$ group compared to the control, but the $P$-value for these genes was less than 0.05 in the $10,000 \mathrm{mg} / \mathrm{kg} \mathrm{Pb}^{2+}$ group (Fig. 5b).

To determine whether these six tartary buckwheat genes were upregulated in response to $\mathrm{Pb}$ tolerance, these genes were heterologously expressed in the $\mathrm{Pb}$-sensitive yeast strain $\Delta y c f 1$. The results suggested that the expression of FtMTPC2, FtPCSL, FtVCE1a, FtNramp3 and FtPCS strongly increased the $\mathrm{Pb}$ tolerance of this strain (Fig. 6). However, compared to the strain harbouring the empty vector (pYES2), $\Delta y c f 1$ cells expressing FtZFP14 were highly sensitive on medium supplemented with 0.04 and 0.08 $\mathrm{mmol} / \mathrm{L} \mathrm{Pb}^{2+}$ (Fig. 6a), with very little growth on the latter 
Table 3 Common KEGG pathway enrichment for CK vs Pb1 and CK vs Pb2

\begin{tabular}{|c|c|c|c|c|}
\hline Pathway & Pathway ID & DEGs & All Genes & $P$-value* \\
\hline Plant hormone signal transduction & ko04075 & $82 / 1674$ & $412 / 26443$ & 0 \\
\hline Plant-pathogen interaction & ko04626 & $56 / 1674$ & $305 / 26443$ & 0 \\
\hline MAPK signalling pathway - plant & ko04016 & $65 / 1674$ & $297 / 26443$ & 0 \\
\hline Phenylpropanoid biosynthesis & ko00940 & $45 / 1674$ & $243 / 26443$ & $2.86336 \mathrm{E}-10$ \\
\hline Carotenoid biosynthesis & ko00906 & $15 / 1674$ & $53 / 26443$ & 1.44839E-05 \\
\hline Starch and sucrose metabolism & ko00500 & $47 / 1674$ & $360 / 26443$ & 3.96627E-05 \\
\hline Sesquiterpenoid and triterpenoid biosynthesis & ko00909 & $11 / 1674$ & $37 / 26443$ & 0.000193512 \\
\hline Sulfur metabolism & ko00920 & $15 / 1674$ & $76 / 26443$ & 0.001038156 \\
\hline Galactose metabolism & ko00052 & $25 / 1674$ & $174 / 26443$ & 0.001215084 \\
\hline Monobactam biosynthesis & ko00261 & $8 / 1674$ & $25 / 26443$ & 0.00133657 \\
\hline Flavonoid biosynthesis & ko00941 & $15 / 1674$ & $84 / 26443$ & 0.002444545 \\
\hline Linoleic acid metabolism & ko00591 & $7 / 1674$ & $26 / 26443$ & 0.008793403 \\
\hline Stilbenoid, diarylheptanoid and gingerol biosynthesis & ko00945 & $10 / 1674$ & $53 / 26443$ & 0.013306974 \\
\hline Zeatin biosynthesis & ko00908 & $6 / 1674$ & $21 / 26443$ & 0.013521575 \\
\hline Alpha-linolenic acid metabolism & ko00592 & $13 / 1674$ & $86 / 26443$ & 0.022189488 \\
\hline DNA replication & ko03030 & $15 / 1674$ & $109 / 26443$ & 0.026250947 \\
\hline Circadian rhythm - plant & ko04712 & $12 / 1674$ & $82 / 26443$ & 0.036475901 \\
\hline
\end{tabular}

* Pathways with $P$-values $\leq 0.05$ are significantly enriched in DEGs

plate. Compared to cells grown on agar-solidified medium, FtZFP14-expressing cells cultured in liquid medium supplemented with $0.04 \mathrm{mmol} / \mathrm{L} \mathrm{Pb}^{2+}$ showed little growth after 48 h (Fig. 6b, c).

\section{Discussion}

Similar to common buckwheat, tartary buckwheat displays high ability to accumulate $\mathrm{Pb}$ in contaminated soil $[21,22]$. In comparison with previous studies, we first demonstrated that tartary buckwheat could grow in soil with a high concentration of $\mathrm{Pb}(10,000 \mathrm{mg} / \mathrm{kg})$. Subsequently, we used TEM to show that tartary buckwheat primarily accumulates $\mathrm{Pb}$ in the vacuoles of leaves. Although many $\mathrm{Pb}$ ions were observed to be absorbed through roots and were present in the cell wall and intercellular spaces, these ions were not stored in root cells and were ultimately transported to leaf vacuoles. Moreover, in order to make clear the mechanism of the tolerance and accumulation of tartary buckwheat leaves under $\mathrm{Pb}$ stress, we carried out transcriptome analysis in different concentration of $\mathrm{Pb}$ ions. In this study, it
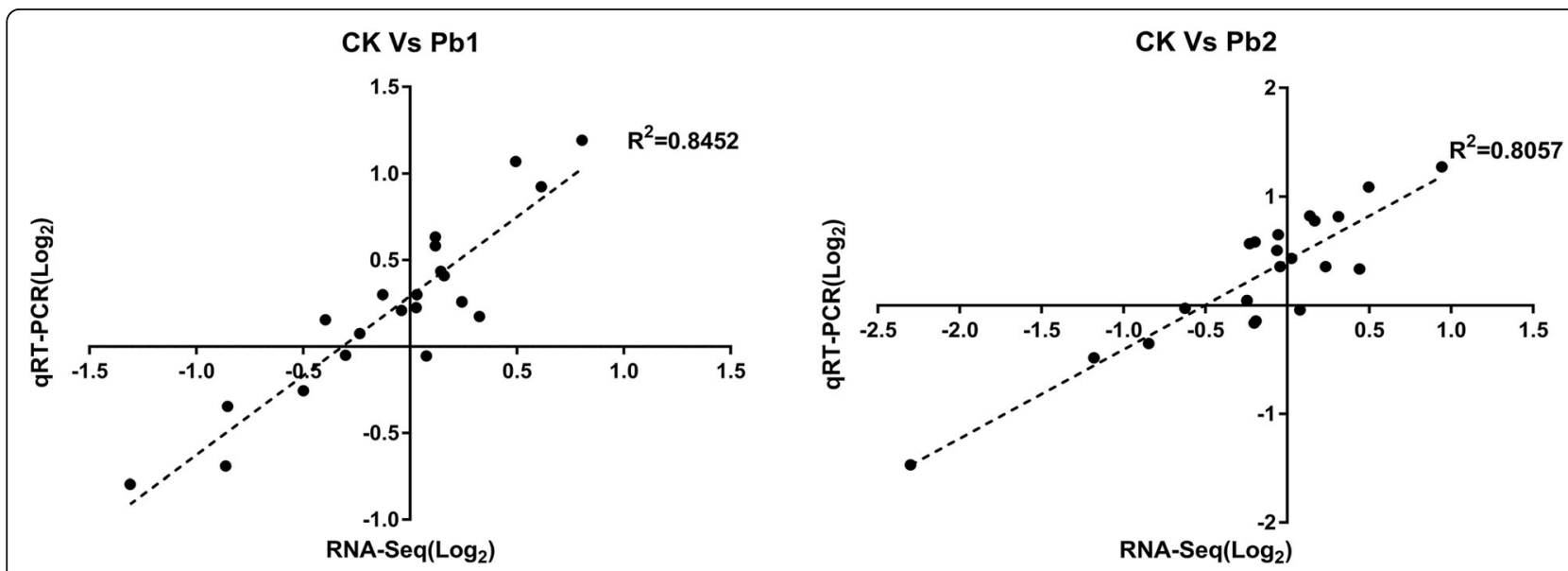

Fig. 4 Validation of gene expression ratios between the RNA-Seq and qRT-PCR analyses. Fifteen randomly selected genes were used to examine expression profiles by qRT-PCR using the same RNA employed for RNA-Seq. Each average RNA-Seq expression value was plotted against the corresponding qRT-PCR value and fitted into a linear regression. Both the $x$ - and $y$-axes are shown on the log2 scale. Each qRT-PCR was performed with three biological replicates 


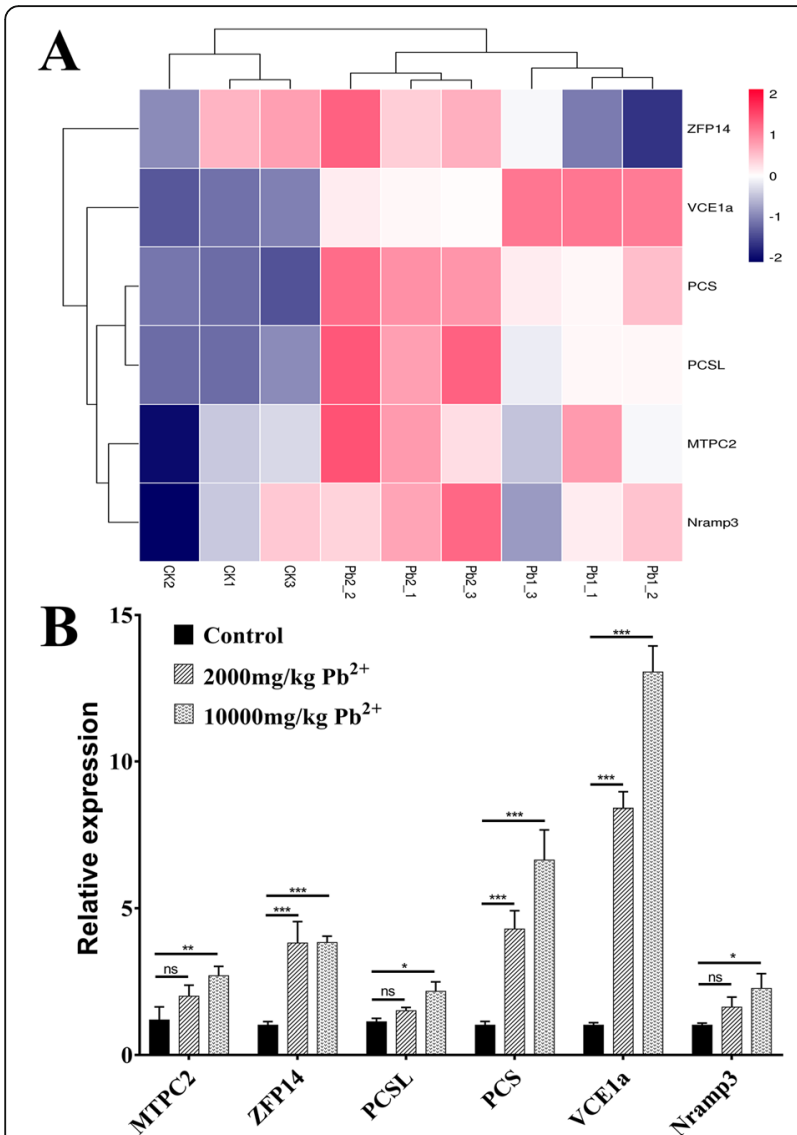

Fig. 5 Heat map of the expression levels of 6 DEGs by FPKM (a) and by qRT-PCR analysis (b). The data shown are the average of three independent experiments. The error bars indicate the standard deviations of the mean. ${ }^{* *}, P<0.001 ;{ }^{* *}, P<0.01 ;{ }^{*}, P<0.05$; ns, not significant

generated 88,977 unigenes that comprised $125,203,555 \mathrm{bp}$ and had an average length and N50 of 982.34 bp and 1730 bp, respectively. Our study produced longer sequences and deeper coverage than prior studies with tartary buckwheat $[29,30]$ (Table 4). Taken together, our present results will not only show a clear physiological understanding of $\mathrm{Pb}$ toxicity but provide a valuable database platform for $\mathrm{Pb}$ stress research.

As the first barrier of cells, the cell wall protects against $\mathrm{Pb}$ entry into the cytoplasm [31]. The cell wall contains polysaccharides and proteins that may serve as binding sites for $\mathrm{Pb}$ ions [32]. When metal ions are deposited on the cell wall, their ability to be transported across the membrane into the protoplast is greatly limited, allowing the normal metabolism of plant cells to be maintained [33]. Here, the cellular component group particularly enriched by $\mathrm{Pb}$ exposure contained genes encoding cell wall (GO: 0005618) and membrane part (GO: 0044425). In addition, genes related to synthesis of polysaccharides (GO: 0005976, GO: 0044264, GO:
0033692 and GO:0010383) increases in response to $\mathrm{Pb}$ stress, causing the cell wall to thicken considerably. Similar observations have been reported for $\mathrm{Pb}$ toxicity in Allium cepa [34]. We also found that a number of genes associated with changes in organelle membranes and cellular macromolecule metabolic were affected by $\mathrm{Pb}$ exposure (Additional file 6: Table S3). Zheng et al. [35] observed that $\mathrm{Pb}$ is transported through the apoplastic and symplastic pathways and is detoxified via cell wall sequestration, autophagy and vacuolar compartmentalization as $\mathrm{Pb}$-phosphate. Furthermore, when such binding sites on the cell walls are saturated, excess $\mathrm{Pb}$ ions are transferred into the cytoplasm and organelles, i.e., vacuoles and the Golgi apparatus [36, 37]. These organelles show reduced direct contact between $\mathrm{Pb}$ ions and enzymes, which prevents enzyme inactivation and blocks biochemical reactions [38]. Accordingly, the cell wall, membrane and organelle work together for the protection of cells under $\mathrm{Pb}$ stress.

In response to lead exposure, plants increased the production of ROS by activating different antioxidant enzymes. Overproduction of reactive oxygen species (ROS), which is caused by many environmental stresses (drought, salinity, temperature, flooding and heavy metals), perturbs the structural and functional stability of membrane proteins and disrupts cellular homeostasis [39-41]. The antioxidant system is an important pathway for protecting the cell membrane from injury due to high levels of hydrogen peroxide, superoxide anion and singlet oxygen under $\mathrm{Pb}$ stress $[42,43]$. In this study, we identified 19 DEGs in tartary buckwheat leaves that were involved in the peroxisome (ko04146) (Additional file 6: Table S3), which is consistent with the increased antioxidant activities reported in previous studies [44, 45]. Venkatachalam et al. [15] found that the accumulation of $\mathrm{Pb}$ in plant tissues leads to increases in catalase (CAT), peroxidase (POD) and ascorbate peroxidase (APX) activities. Wang et al. [46] demonstrated that $\mathrm{Pb}$ could cause oxidative damage and increase superoxide dismutase (SOD), CAT, POD, glutathione reductase (GR), and APX activities as well as the levels of monodehydroascorbate reductase (MDA) and nonprotein thiols.

Photosynthesis is a highly integrated and regulated process, and the response of photosynthesis to environmental changes is inhibited by heavy metals such as $\mathrm{Pb}$ [47, 48]. Chen et al. [49] reported that in rice, the most basic and apparent symptoms of $\mathrm{Pb}$-induced toxicity include leaf chlorosis; stunting; reduced net photosynthesis, stomatal conductance, and leaf transpiration; and less accumulation of photosynthetic pigments such as chlorophyll (Chl) a, Chl b and carotenoids. Furthermore, by maintaining the balance of photosynthetic energy, increases in chlorophyll content and the number of chloroplasts may enhance plant tolerance to $\mathrm{Pb}[16,26]$. In 

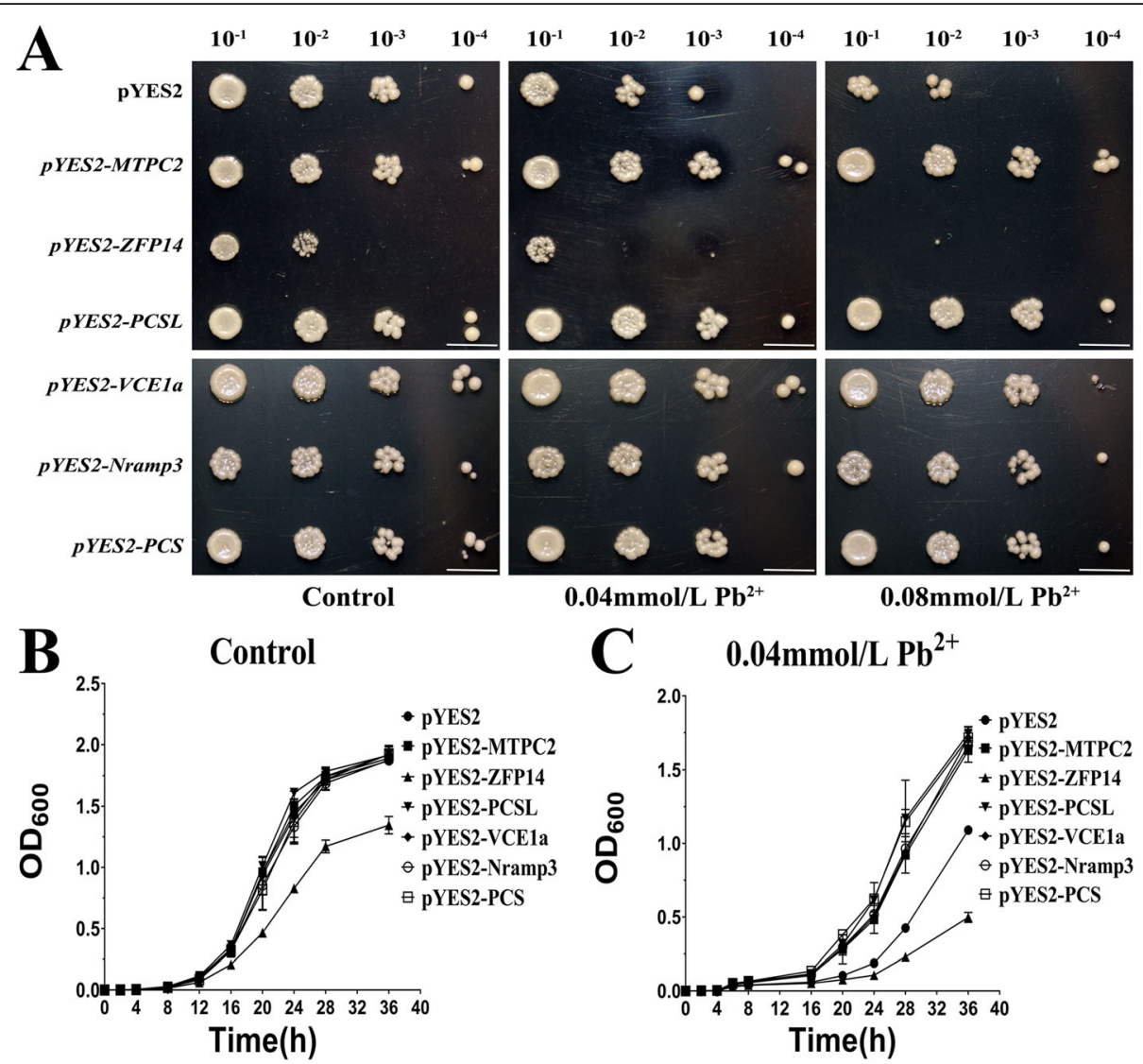

Fig. 66 Upregulated genes contribute to enhanced tolerance to Pb in yeast. a The $\triangle y c f 1$ strain was transformed with (pYES2), pYES2-FtMTPC2, pYES2-FtZFP14, pYES2-FtPCSL, pYES2-FtVCE1a, pYES2-FtNramp3, or pYES2-FtPCS and grown on SD-Ura (2\% galactose) plates with 0, 0.04, or 0.08 $\mathrm{mmol} / \mathrm{L} \mathrm{Pb^{2+ }}$ for 4 days. Bar $=1 \mathrm{~cm}$. b, c Growth curve of strains expressing the 6 upregulated F. tataricum genes under $0,0.04 \mathrm{mmol} / \mathrm{L} \mathrm{Pb}{ }^{2+}$. The data are presented as the mean $\pm \mathrm{SD}(n=3)$

our study, the 'photosynthesis' (ko00195) KEGG pathway was enriched (Additional file 6: Table S3), and a number of DEGs common to both the $\mathrm{CK}$ vs $\mathrm{Pb} 1$ and $\mathrm{CK}$ vs $\mathrm{Pb} 2$ comparisons were involved in the photosystem (PS) II, PS I and F-type ATPase pathways. The major effects of $\mathrm{Pb}$ stress in plants involve potential damage to the oxygen-evolving complex (OEC) and the inhibition of PS I and II activity [50]. In accordance with this notion, five genes involved in the PS I and PS II pathways were downregulated with different fold changes based on our transcriptome results. Similarly, almost all of these DEGs, including the PSII core proteins D1, D2, CP43 and $\mathrm{CP} 47$, which are considered to have the closest relationship with oxygen production, were downregulated [51]. Therefore, impaired photosynthesis is a way to reduce oxygen production and protect against oxidative damage by reducing the related genes in chloroplasts. Taken together, these results suggest that the regulation of the photosynthesis pathway may be a common response to $\mathrm{Pb}$ stress among various plant species.

Together with the wide range of adaptive strategies induced by $\mathrm{Pb}$ stress, the plants are able to acquire other detoxification and defence mechanisms through gene regulation. On one hand, plant possesses a nonenzymatic

Table 4 Comparison of our sequencing data with other sequencing data

\begin{tabular}{llll}
\hline Database & This research & Chen's research & Yao's research \\
\hline Species & Fagopyrum tataricum & Fagopyrum tataricum & Fagopyrum tataricum \\
Cultivars of buckwheat & Jiujiang & N/A & Heifeng No. 1 and Xiqiao No. 2 \\
Number of unigenes generated & 88,977 & 45,278 & 57,800 \\
Total unigene length (bp) & $125,203,555$ & $42,818,102$ & $55,189,159$ \\
Average length (bp) & 982.34 & 862 & 954.83 \\
N50 (bp) & 1730 & 1476 & 1676 \\
\hline
\end{tabular}


antioxidative mechanism of defence against $\mathrm{Pb}$ exposure [52]. Our result showed that the phenylpropanoid biosynthesis (ko00940) was one of the most significantly enriched with DEGs in the tartary buckwheat leaves under $\mathrm{Pb}$ stress (Table 3 and S4). In this pathway, phenylalanine ammonium lyase (PAL) is the key regulatory enzyme in altering the biosynthesis and accumulation of flavonoids and lignin [53]. Moreover, the branched biochemical reactions of phenylpropanoid biosynthesis, including flavonoid biosynthesis (ko00941) and carotenoid biosynthesis (ko00906), providing a number of important phenolic compounds (anthocyanin, carotenoids and flavonoids) [54]. These metabolites protect the plant against $\mathrm{Pb}$ induced oxidative stress by scavenging $\mathrm{H}_{2} \mathrm{O}_{2}$ and active free radicals [55]. On the other hand, the initial perception of plants to heavy metal can trigger signal transduction, and initiate gene expression and cellular processes involved in acclimation to stress. Environmental stressors are transmitted through hormone signalling and MAP kinase (MAPK) pathways to target transcription factors (TFs) [56]. Plant hormones are signalling molecules in plants exposed to various tolerances, including $\mathrm{Pb}$ stress. The hormones related to heavy metals include abscisic acid (ABA), auxin, jasmonic acid (JA), and salicylic acid (SA) [57]. Under HMs stress, the plant hormone concentration was elevated, thereby upregulating the expression of MAPKs and GSH-metabolic genes and stimulating GSH biosynthesis, which is involved in signalling pathways and stress responses [58]. In our study, a majority of DEGs were enriched in the pathways involved in plant hormone signal transduction, MAPK signalling and glutathione metabolism (Table S4). Therefore, signalling from upstream second messengers and hormones is transduced to downstream acceptors (MAPKs). The MAPK signalling pathways play a pivotal role in this process and interact with other signalling molecules to mediate crosstalk among plant signalling systems to facilitate adaptation and coordinate plant responses to various stressors [59].

Moreover, some DEGs that were not significantly enriched according to GO or KEGG analyses may nonetheless be involved in regulating $\mathrm{Pb}$ tolerance and hyperaccumulation under $\mathrm{Pb}$ stress. Phytochelatins (PCs), which are synthesized from glutathione (GSH) by phytochelatin synthetase (PCS) [60], form mercaptide bonds with various metals and are ultimately transported into the vacuolar space $[61,62]$. To the results of previous studies, natural resistance-associated macrophage proteins (Nramps) [63, 64], metal tolerance protein (MTP) $[65,66]$ and vacuole transporter (YCF) [67] are all membrane transporters that have been proved to enhance the tolerance or hyperaccumulation in plant. To verify whether these genes participate in the same process in tartary buckwheat, these genes were heterologously expressed in yeast, and the results were consistent with the above mechanism (Fig. 6).

Based on the present results, we inferred that a variety of metabolic processes in tartary buckwheat leaves are affected during $\mathrm{Pb}$ stress. As illustrated in Fig. 7, after $\mathrm{Pb}$ ions are transported to the leaves from the roots, a portion of $\mathrm{Pb}$ ions bind to cell walls. Moreover, the vast majority of these ions are transported into the cytoplasmic matrix by cation diffusion facilitators (CDFs), Nramps and other ion transporters through iron or water channels [68]. Once $\mathrm{Pb}$ ions enter plant cells, the concentrations of plant hormones change, which results in the accumulation of GSH. ROS interact with plant hormones and participate in MAPK cascades to activate TFs. Consequently, the genes that changed in response to $\mathrm{Pb}$ stress were regulated by TFs to defend against and mitigate $\mathrm{Pb}$ exposure. Subsequently, cells maintain the cellular homeostasis by antioxidative enzymes, including APX, CAT, SOD, POD, and GR, in all types of

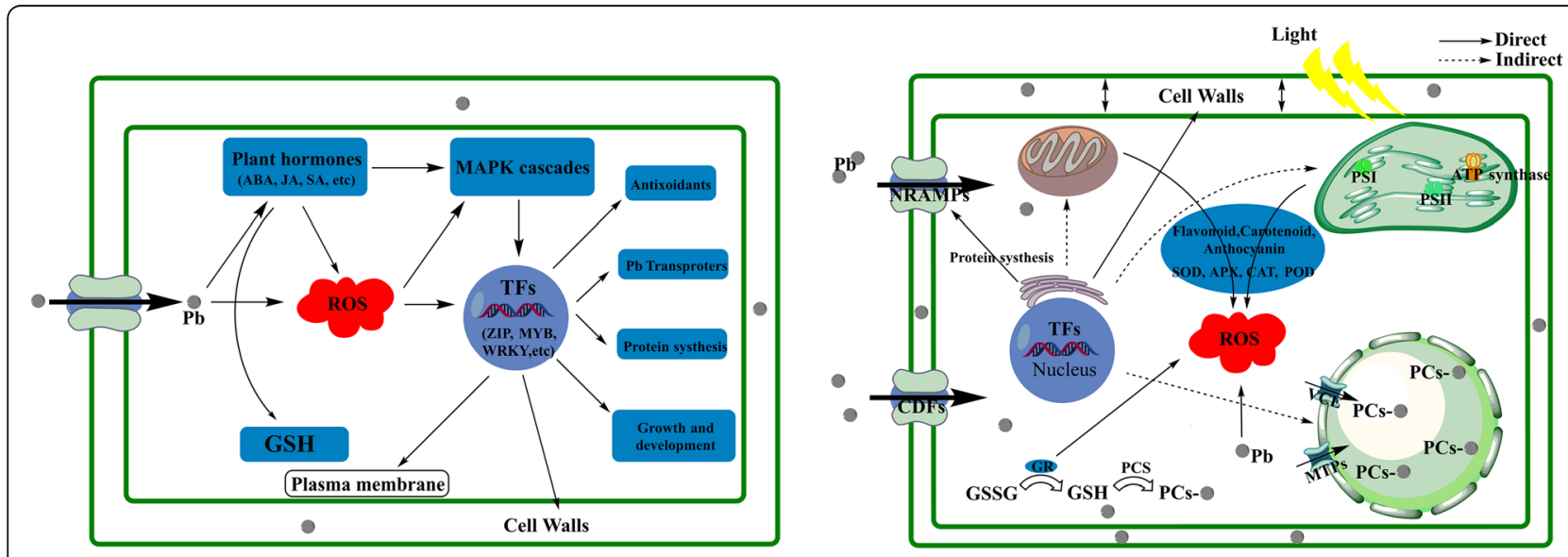

Fig. 7 Schematic diagram of the response to $\mathrm{Pb}^{2+}$ in the leaves of $F$. tataricum 
organelles. Then, $\mathrm{Pb}$ ions are chelated by GSH, PCs and other compounds and are then transported into vacuoles by VCE (a homologue of YCF), MTPs and related transporters. These findings suggest the metabolic process involved in the $\mathrm{Pb}$ response of tartary buckwheat leaves and the transport and accumulation of $\mathrm{Pb}$ ions.

\section{Conclusions}

In summary, the results of our study show that tartary buckwheat leaves are the primary storage tissue for $\mathrm{Pb}$ and provide transcriptome data for tartary buckwheat leaves in response to $\mathrm{Pb}$ stress. Furthermore, we identified 374 DEGs that were significantly associated with the primary events of $\mathrm{Pb}$ exposure and the response to $\mathrm{Pb}$ treatment during the early growth stage of tartary buckwheat leaves. According to GO and KEGG pathway enrichment analyses, these DEGs are primarily associated with primary defence mechanisms, such as cell walls, plant hormone signal transduction, the antioxidant system and photosynthesis. In addition, these DEGs are involved in hyperaccumulation mechanisms, e.g., TFs, metal iron binding and membrane transport proteins, as demonstrated by their heterologous expression in yeast. This study specifically explored the fundamental $\mathrm{Pb}$ tolerance and hyperaccumulation mechanisms in the leaves of tartary buckwheat, providing new information for further research on the molecular mechanisms of the response to $\mathrm{Pb}$ stress in tartary buckwheat.

\section{Methods}

\section{Plant materials and growth conditions}

The Fagopyrum tataricum 'Jiujiang' cultivar used in the present study was acquired from the Yan Chai Lab of Northwest A\&F University. The seed growth conditions were similar to those described by Tamura [21], with some changes. Seeds were prevernalized at $4{ }^{\circ} \mathrm{C}$ for one week, soaked in deionized water for $2 \mathrm{~h}$ at $45^{\circ} \mathrm{C}$, and sown into $40 \mathrm{~g}$ PEAT substrate (PINDSTRUP, Latvia; https://www. pindstrup.com/) without any heavy metal pollution, with four seeds per pot $(30 \mathrm{~cm}$ diameter). The plants were grown in a greenhouse at $60 \%$ relative humidity with $12 \mathrm{~h}$ of light and a $25 / 15^{\circ} \mathrm{C}$ artificial day/night air temperature. After culture for 15 days, the cotyledons of buckwheat had completely unfolded, and the plants were treated with 0 , $1000,2000,5000$, or $10,000 \mathrm{mg} / \mathrm{kg} \mathrm{Pb}\left(\mathrm{NO}_{3}\right)_{2}$ depending on the dry weight of the substrate soil. Each group was repeated ten times. According to the previous study [21], we chose and collected leaf tissue samples $72 \mathrm{~h}$ after treatment with 0,2000 , or $10,000 \mathrm{mg} / \mathrm{kg} \mathrm{Pb}\left(\mathrm{NO}_{3}\right)_{2}$ for Illumina deep sequencing (three biological replicates) and qRT-PCR validation (three biological replicates). We defined the $0 \mathrm{mg} / \mathrm{kg}$ $\mathrm{Pb}\left(\mathrm{NO}_{3}\right)_{2}$ treatment as the control 'CK', the $2000 \mathrm{mg} / \mathrm{kg}$ $\mathrm{Pb}\left(\mathrm{NO}_{3}\right)_{2}$ treatment as ' $\mathrm{Pbl}$ ', and the $10,000 \mathrm{mg} / \mathrm{kg} \mathrm{Pb}$ $\left(\mathrm{NO}_{3}\right)_{2}$ treatment as ' $\mathrm{Pb} 2$ '. The samples were immediately frozen in liquid nitrogen and stored at $-80^{\circ} \mathrm{C}$ until use. The remaining plants were continuously cultivated and harvested before anthesis to assess the accumulation of $\mathrm{Pb}$ in plant materials. The plant materials were washed with deionized water and dried for $48 \mathrm{~h}$ at $80^{\circ} \mathrm{C}$, after which they were weighed, ground in a mill, and then digested with concentrated $\mathrm{HNO}_{3}: \mathrm{HClO}_{4}$ (4:1) in a microwave oven. After digestion, the solution was diluted to $25 \mathrm{~mL}$ with $1 \%$ $\mathrm{HNO}_{3}$ and filtered. Subsequently, the samples were analysed using a Hitachi Z-2000 atomic absorption spectrometer (Hitachi, Japan).

\section{Ultrastructural localization of $\mathrm{Pb}$ using TEM}

This part references Małgorzata's method [69] with some changes. One- to two-millimetre sections of the control and $10,000 \mathrm{mg} / \mathrm{kg} \mathrm{Pb}\left(\mathrm{NO}_{3}\right)_{2}$-treated leaves, stems, and roots were fixed in $4 \%$ glutaraldehyde $(\mathrm{v} / \mathrm{v})$ in $0.2 \mathrm{~mol} / \mathrm{L}$ sodium phosphate buffer $(49 \mathrm{~mL} 0.2 \mathrm{~mol} / \mathrm{L}$ $\mathrm{Na}_{2} \mathrm{HPO}_{4} \cdot 12 \mathrm{H}_{2} \mathrm{O}$ with $51 \mathrm{~mL} \mathrm{NaH} \mathrm{PO}_{4} \cdot 2 \mathrm{H}_{2} \mathrm{O}$ in a total of $100 \mathrm{~mL}$ ) at $\mathrm{pH} 6.8$ at $4{ }^{\circ} \mathrm{C}$ for $12 \mathrm{~h}$. The tissues were rinsed with $0.1 \mathrm{~mol} / \mathrm{L}$ phosphate buffer $(\mathrm{pH} 6.8)$ six times (10 min each time) at room temperature, postfixed in $1 \%(\mathrm{v} / \mathrm{w}) \mathrm{OsO}_{4}$ at $4{ }^{\circ} \mathrm{C}$ for $2 \mathrm{~h}$ and then rinsed six times (10 min each time) in $0.1 \mathrm{~mol} / \mathrm{L}$ phosphate buffer solution ( $\mathrm{pH}$ 6.8). The samples were dehydrated using graded acetone and ethanol series $(30,50,70,80$ and $90 \%$ ) at room temperature, infiltrated, embedded in LR white resin and cut into ultrathin sections $(\sim 90 \mathrm{~nm})$ using a Leica EM UC7 microtome (Leica, Nussloch, Germany). The sections were collected on copper grids, dusted with coal, and finally observed using a JEOL JEM-1230 transmission electron microscope (JEOL, Tokyo, Japan) at an accelerating voltage of $80 \mathrm{keV}$.

RNA extraction, cDNA library preparation and sequencing Total RNA was extracted from frozen leaf tissue using the Quick RNA isolation kit (Huayueyang, Beijing, China), which uses RNase-free DNase I to remove residual genomic DNA. The RNA quantities and qualities were assessed using an Agilent Bioanalyzer 2100 (Agilent Technologies, Santa Clara, CA, USA), and the RIN values were greater than 7 . RNA integrity was assessed by agarose gel electrophoresis ( $1 \%$ gel with the addition of SYBR Green dye). To obtain a global and high-quality overview of the tartary buckwheat transcriptome, individual RNAs from leaf tissues from three biological replicate plants exposed to three $\mathrm{Pb}$ concentrations were used for library construction.

cDNA libraries were constructed using a TruSeq ${ }^{\text {Th }}$ RNA Sample Prep kit (Illumina, USA) following the manufacturer's instructions. Briefly, mRNA was purified from total RNA using Dynabeads oligo (dT)25 (Life Technologies, USA). Subsequently, poly(A) mRNA was purified from $25 \mu \mathrm{g}$ of pooled total RNA using oligo 
(dT) magnetic beads and was cut into short fragments of approximately $300 \mathrm{bp}$ in fragmentation buffer. The resulting mRNA was fragmented and reverse transcribed into first-strand cDNA using random hexamer primers, after which second-strand cDNA was synthesized. The double-stranded cDNA was purified and ligated to adaptors for Illumina paired-end sequencing. After agarose gel electrophoresis, suitable fragments (>200 bp) were chosen for PCR amplification to create the final cDNA libraries. The resulting cDNA libraries were sequenced at Shanghai Majorbio Biopharm Technology Co., Ltd. (Shanghai, China) using an Illumina HiSeq 4000 sequencing system.

\section{Data filtering, de novo assembly and annotation}

The raw image data from Illumina sequencing were transformed into raw reads by base calling. The raw reads were filtered to obtain high-quality clean data and assembled using the program Trinity (Version: V2.5.0) [70] to generate contigs. Redundant sequences were removed, and the resulting contigs were connected into scaffolds to obtain unigenes. The raw data were deposited in the National Center for Biotechnology Information (NCBI) Sequence Read Archive (SRA) (Accession Number: PRJNA515389). Before functional annotation, the assembled transcripts (unigenes) were analysed using Trinity (http://trinityrnaseq.sourceforge.net/analysis/extract_proteins_from_trinity_transcripts.html) to predict open reading frames (ORFs). All nine libraries were assembled using the Trinity method due to the low quality of the reference genome database for tartary buckwheat. The functional annotations of all the unigenes were compared with sequences in the NR protein database (http://www.ncbi.nlm.nih.gov/), Clusters of Orthologous Groups (COG) protein database (http://www.ncbi.nlm. nih.gov/COG/), and KEGG database (http://www.genome.jp/kegg/) using BLASTx (E-value) [71]. The Blast2GO program (Version: 2.5.0) was used to analyse GO annotations for the unigenes. Functional annotations were performed by aligning the unigenes to those present in the NCBI nonredundant (NR), COG, GO, String, Swiss-Prot and KEGG databases, with an E-value of <1e-5 (Additional file 7: Table S4). The number of unigenes associated with each GO term was then calculated for the $\mathrm{BP}, \mathrm{MF}$, and $\mathrm{CC}$ categories. The unigene sequences were also aligned to the COG database to predict and classify potential functions. In addition, the COG and KEGG databases were used to complement the GO functional characterizations and determine the sequence directions of the unigenes.

\section{DEGs and enrichment analysis}

All clean sequence reads were mapped back to the transcriptome assembly using Bowtie2 (Version: 2.3.4) [72], and the read counts were then normalized as transcripts per million reads (FPKM) to calculate the unigene expression level by RSEM (http://deweylab.biostat.wisc. edu/rsem/) (Version: 1.2.31). The DEGs among the three samples were analysed via gene read counts using edge $R$ (http://www.bioconductor.org/packages/2.12/bioc/html/ edgeR.html) (Version: 3.14.0) under the following standard parameters: FDR $<0.05$ and $\log 2|\mathrm{FC}|>=1$. GO and KEGG pathway enrichment analyses were conducted via hypergeometric distribution testing using GOATOOLS tools (Version: 0.6.5). BH (fdr correction with Benjamini/Hochberg) correction was used to adjust $P$-values. Functional clusters were considered significantly enriched when the corrected $\mathrm{P}$-value was smaller than 0.05 .

\section{qRT-PCR validation and expression analysis}

Twenty-one genes, including 15 DEGs, were randomly selected, and $6 \mathrm{~Pb}$-regulated genes were used for further validation by qRT-PCR. Total RNA extraction and genomic DNA removal were performed as described above. First-strand cDNA was synthesized from $1 \mu \mathrm{g}$ of RNA using a $\mathrm{HiScript}^{\circ}$ 1st Strand cDNA Synthesis kit (Vazyme, China). The cDNA products were then diluted tenfold with nuclease-free water for use as a template for qRT-PCR, which was performed using the ChamQ ${ }^{\mathrm{m}}$ SYBR Green Master mix (Vazyme, China) with a CFX96 Real-Time PCR Detection System (Bio-Rad). The specific primer pairs used for qRT-PCR are listed in Additional file 8: Table S5. For qRT-PCR validation, the primer specificity was tested by PCR (Additional file 9: Figure S4). All samples were normalized to the CACS gene [73]. The DEG expression fold change was calculated based on the threshold cycle $(\mathrm{Ct})$, where $\Delta \mathrm{Ct}=$ $\mathrm{Ct}_{\text {target }}-\mathrm{Ct}_{\mathrm{CACS}}$ and $\Delta(\Delta \mathrm{Ct})=\Delta \mathrm{Ct}_{\text {Control }}-\Delta \mathrm{Ct}_{\text {Indicated }}$ condition.

\section{$\mathrm{Pb}$ resistance in yeast cells}

The coding sequences of FtMTPC2, FtZFP14, FtPCSL, FtVCE1a, FtNramp3, and FtPCS1 from the cDNA library constructed by RNA-Seq were amplified, and the fragments were subcloned into pEASY-Blunt Zero (TransGen Biotech, China) and sequenced. The correct coding DNA sequence (CDS) fragments were cloned into a pYES2 vector using the ClonExpress II One Step Cloning kit (Vazyme, China) for expression in yeast. Cells of the $\mathrm{Pb}$ - and cadmium-sensitive yeast strain

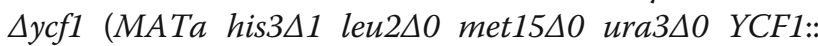
kanMX4) carrying the empty vector (pYES2), pYES2FtMTPC2, pYES2-FtZFP14, pYES2-FtPCSL, pYES2FtVCE1a, pYES2-FtNramp3, or pYES2-FtPCS were grown in medium at $30^{\circ} \mathrm{C}$. To analyse $\mathrm{Pb}$ resistance, the yeast cells were cultured in SD-Ura ( $2 \%$ glucose $)$ medium at $30{ }^{\circ} \mathrm{C}$ until reaching an $\mathrm{OD}_{600}$ of 2.0 and 
then serially diluted $\left(10^{-1}, 10^{-2}, 10^{-3}, 10^{-4}\right)$ with $1 \times \mathrm{TE}$ buffer. The cells were spotted onto an SD-Ura ( $2 \%$ galactose) medium plate with $\mathrm{Pb}^{2+}(0,40$, or $80 \mu \mathrm{mol} / \mathrm{L})$ and cultured at $30^{\circ} \mathrm{C}$ in an incubator for $4 \mathrm{~d}$. Yeast cells were inoculated onto SD-Ura (2\% galactose) medium with 0 or $40 \mu \mathrm{mol} / \mathrm{L} \mathrm{Pb}^{2+}$ at a $1: 1000$ ratio to determine the growth curve.

\section{Data analysis}

All values are expressed as the mean \pm standard deviation from three individual experiments. The data analysis was performed using one-way analysis of variance (ANOVA) followed by Tukey's test with GraphPad Prism 6. Differences were considered significant at $P<0.05$.

\section{Supplementary information}

Supplementary information accompanies this paper at https://doi.org/10. 1186/s12870-020-2265-1.

Additional file 1: Figure S1. Physiological aspects of tartary buckwheat leaves under $\mathrm{Pb}$ stress at different concentrations.

Additional file 2: Figure S2. Sequence length distribution of the unigenes.

Additional file 3: Table S1. Annotations of all unigenes.

Additional file 4: Figure S3. Species and similarity distribution based on the best hit.

Additional file 5: Table S2. Common regulated genes in the CK vs Pb1 and $\mathrm{CK}$ vs Pb2 comparisons.

Additional file 6: Table S3. GO enrichment analysis of DEGs.

Additional file 7: Table S4. KEGG pathway enrichment analysis of DEGs.

Additional file 8: Table S5. Primers used for quantitative real-time PCR analysis.

Additional file 9: Figure S4. The primer specificity test for $\mathrm{QPCR}$ validation.

\begin{abstract}
Abbreviations
AAS: Atomic absorption spectrophotometry; Al: Aluminium; APX: Ascorbate peroxidase; BP: Biological process; BZIP: Basic region-leucine zipper; CAT: Catalase; CC: Cellular component; DEGs: Differentially expressed genes; DMT: Divalent metal transporter; ERF: Ethylene-responsive factor; FPKM: Reads per kilobase of exon per million reads mapped; GARP: Glutamic acid-rich protein; GO: Gene Ontology; GR: Glutathione reductase; GSH: Glutathione; KEGG: Kyoto Encyclopedia of Genes and Genomes; MDA: Monodehydroascorbate reductase; MF: Molecular function; MTPC2: Metal transporter protein C2; NGS: Next-generation sequencing; NR: Nonredundant protein database; Nramp3: Natural resistance-associated macrophage protein 3; OEC: Oxygen-evolving complex; ORFs: Open reading frames; Pb: Lead; PCS: Phytochelatin synthetase; PCs: Phytochelatins; PCSL: Phytochelatin synthetase-like family protein; POD: Peroxidase; PS: Photosystem; qRT-PCR: Quantitative real-time PCR; RNA-Seq: RNA deep sequencing; ROS: Reactive oxygen species; RSEM: RNA-Seq by ExpectationMaximization; SOD: Superoxide dismutase; TEM: Transmission electron microscope; VCE1a: Vacuolar cation/proton exchanger 1a; YCF1: Hypothetical chloroplast open reading frame 1; ZFP14: CCCH-type zinc finger protein 14
\end{abstract}

\section{Acknowledgements}

We are grateful to Professor Tuanyao Chai from the College of Life Science, Graduate University of Chinese Academy of Sciences, for providing us with the pYES2 plasmid and the $\triangle y c f 1$ strain.

\section{Authors' contributions}

PC conceived the study. PC and LW designed the experiments. LW, BZ, and YY performed the experiments. LW and YY analysed the data. PC, QLX and LW wrote the manuscript. All authors read and approved the final manuscript.

\section{Funding}

This work was supported by grants from the National Natural Science Foundation of China (Nos. 30400282 and 31171606) and the Key Research and Development Program of Shaanxi Province (2017NY-033) for collection, analysis and processing of the study. These fundings provided the financial support to the research projects, but did not involve in project design, data collection, analysis, or preparation of the manuscript.

\section{Availability of data and materials}

All data generated or analysed during this study are included in the manuscript and its Additional files. The sequencing dataset used in the study is available in the Sequence Read Archive of the NCBI database under BioProject: PRJNA515389 (https://www.ncbi.nlm.nih.gov/bioproject/ PRJNA515389/), which will be made public after publication.

Ethics approval and consent to participate Not applicable.

\section{Consent for publication}

Not applicable.

\section{Competing interests}

The authors declare that they have no competing interests.

Received: 29 January 2019 Accepted: 23 January 2020

Published online: 03 February 2020

\section{References}

1. Ercal N, Gurer-Orhan H, Aykin-Burns N. Toxic metals and oxidative stress part I: mechanisms involved in metal-induced oxidative damage. Curr Top Med Chem. 2001;1(6):529-539.10.2174/1568026013394831.

2. Shahid M, Pinelli E, Pourrut B, Silvestre J, Dumat C. Lead-induced genotoxicity to Vicia faba $L$. roots in relation with metal cell uptake and initial speciation. Ecotoxicol Environ Saf. 2011;74(1):78-84. https://doi.org/10. 1016/j.ecoenv.2010.08.037.

3. Jarup L. Hazards of heavy metal contamination. Br Med Bull. 2003;68:167-82. https://doi.org/10.1093/bmb/ldg032.

4. Cecchi M, Dumat C, Alric A, Felix-Faure B, Pradere P, Guiresse M. Multi-metal contamination of a calcic cambisol by fallout from a lead-recycling plant. Geoderma. 2008;144(1-2):287-98. https://doi.org/10.1016/j.geoderma.2007. 11.023 .

5. Sharma P, Dubey RS. Lead toxicity in plants. Braz J Plant Physiol. 2005;17(1): 35-52. https://doi.org/10.1590/S1677-04202005000100004.

6. Tangahu BV, Sheikh Abdullah SR, Basri H, Idris M, Anuar N, Mukhlisin M. A Review on heavy metals ( $\mathrm{As}, \mathrm{Pb}$, and $\mathrm{Hg}$ ) uptake by plants through phytoremediation. Int J Chem Eng. 2011;2011:1687-1806X. https://doi.org/ 10.1155/2011/939161.

7. Liu J, Ma X, Wang M, Sun X. Genotypic differences among rice cultivars in lead accumulation and translocation and the relation with grain $\mathrm{Pb}$ levels. Ecotoxicol Environ Saf. 2013;90:35-40. https://doi.org/10.1016/j.ecoenv.2012. 12.007.

8. Gupta DK, Nicoloso FT, Schetinger MRC, Rossato LV, Pereira LB, Castro GY, Srivastava S, Tripathi RD. Antioxidant defense mechanism in hydroponically grown Zea mays seedlings under moderate lead stress. J Hazard Mater. 2009;172(1):479-84. https://doi.org/10.1016/j.jhazmat.2009.06.141.

9. Gupta DK, Huang HG, Yang XE, Razafindrabe BHN, Inouhe M. The detoxification of lead in Sedum alfredii $\mathrm{H}$. is not related to phytochelatins but the glutathione. J Hazard Mater. 2010;177(1):437-44. https://doi.org/10. 1016/j.jhazmat.2009.12.052.

10. Pandey LK, Kumar D, Yadav A, Rai J, Gaur JP. Morphological abnormalities in periphytic diatoms as a tool for biomonitoring of heavy metal pollution in a river. Ecol Indic. 2014;36:272-9. https://doi.org/10.1016/j.ecolind.2013.08.002.

11. Alexander P, Alloway B, Dourado A. Genotypic variations in the accumulation of $\mathrm{Cd}, \mathrm{Cu}, \mathrm{Pb}$ and $\mathrm{Zn}$ exhibited by six commonly grown 
vegetables. Environ Pollut. 2006;144(3):736-45. https://doi.org/10.1016/j. envpol.2006.03.001.

12. Li H, Hu T, Amombo E, Fu J. Transcriptome profilings of two tall fescue (Festuca arundinacea) cultivars in response to lead $(\mathrm{Pb})$ stress. BMC Genomics. 2017;18(1):145. https://doi.org/10.1186/s12864-016-3479-3.

13. Yoon J, Cao X, Zhou Q, Ma LQ. Accumulation of $\mathrm{Pb}, \mathrm{Cu}$, and $\mathrm{Zn}$ in native plants growing on a contaminated Florida site. Sci Total Environ. 2006; 368(2-3):456-64. https://doi.org/10.1016/j.scitotenv.2006.01.016.

14. Ferreyroa GV, Lagorio MG, Trinelli MA, Lavado RS, Molina FV. Lead effects on Brassica napus photosynthetic organs. Ecotoxicol Environ Saf. 2017;140:12330. https://doi.org/10.1016/j.ecoenv.2017.02.031.

15. Venkatachalam P, Jayalakshmi N, Geetha N, Sahi SV, Sharma NC, Rene ER, Sarkar SK, PJC F. Accumulation efficiency, genotoxicity and antioxidant defense mechanisms in medicinal plant Acalypha indica L. under lead stress. Chemosphere. 2017;171:544-53. https://doi.org/10.1016/j.chemosphere.2016. 12.092.

16. Wang L, Yang H, Liu R, Fan G. Detoxification strategies and regulation of oxygen production and flowering of Platanus acerifolia under lead (Pb) stress by transcriptome analysis. Environ Sci Pollut Res. 2015;22(16):1274758. https://doi.org/10.1007/s11356-015-4563-y.

17. Ohnishi O. Search for the wild ancestor of buckwheat. 1. Description of new Fagopyrum (Polygonaceae) species and their distribution in China and the Himalayan hills. Fagopyrum. 1998;15(76):18-28. https://doi.org/10.1007/ BF02861199.

18. Li A, Suk-pyo H. Fagopyrum tataricum. In: Flora of China; 2004

19. Janeš $\mathrm{D}$, Prosen $\mathrm{H}$, Kreft $\mathrm{S}$. Identification and quantification of aroma compounds of tartary buckwheat (Fagopyrum tataricum Gaertn.) and some of its milling fractions. J Food Sci. 2012;77(7):C746-51. https://doi.org/10 1111/j.1750-3841.2012.02778.x.

20. Edwardson S. Buckwheat: pseudocereal and nutraceutical: ASHS press; 1996.

21. Tamura H, Honda M, Sato T, Kamachi H. Pb hyperaccumulation and tolerance in common buckwheat (Fagopyrum esculentum Moench). J Plant Res. 2005;1 18(5):355-9. https://doi.org/10.1007/s10265-005-0229-z.

22. Liu Y, Le YU, Chen Y, Liu X, Lei WU, Huang J, Suping HE. Lead tolerance of different Fagopyrum esculentum cultivars. Chin J Ecol. 2006;25(11):1344-7. https://doi.org/10.1016/S1872-2032(06)60052-8.

23. KOC N, Celık S, Acar R, Kan Y. The determination of some medicinal properties of bermudagrass, white clover and buckwheat using as forage crops. In: VII International Scientific Agriculture Symposium "Agrosym 2016", At Jahorina: University of East Sarajevo, Faculty of Agriculture; 2016. p. 90611. https://doi.org/10.7251/AGRENG1607133.

24. Hernández I, Alegre L, Van Breusegem F, Munné-Bosch S. How relevant are flavonoids as antioxidants in plants? Trends Plant Sci. 2009;14(3):125-32. https://doi.org/10.1016/j.tplants.2008.12.003.

25. Wu Q, Bai X, Zhao W, Xiang D, Wan Y, Yan J, Zou L, Zhao G. De Novo Assembly and Analysis of Tartary Buckwheat (Fagopyrum tataricum Garetn.) Transcriptome Discloses Key Regulators Involved in Salt-Stress Response. Genes. 2017:8(10):255. https://doi.org/10.3390/genes8100255.

26. Tian S, Gu C, Liu L, Zhu X, Zhao Y, Huang S. Transcriptome profiling of Louisiana iris root and identification of genes involved in lead-stress response. Int J Mol Sci. 2015;16(12):28087-97. https://doi.org/10.3390/ ijms161226084.

27. Gao J, Zhang Y, Lu C, Peng H, Luo M, Li G, Shen Y, Ding H, Zhang Z, Pan G. The development dynamics of the maize root transcriptome responsive to heavy metal Pb pollution. Biochem Biophys Res Commun. 2015;458(2):28793. https://doi.org/10.1016/j.bbrc.2015.01.101

28. Auguy F, Fahr M, Moulin P, El Mzibri M, Smouni A, Filali-Maltouf A, Béna G, Doumas P. Transcriptome changes in Hirschfeldia incana in response to lead exposure. Front Plant Sci. 2016;6:1231. https://doi.org/10.3389/fpls.2015.01231

29. C-x C, Li Q, Y-x G, C-I D, Z-g D, EMS P. Transcriptome Analysis of Germinated Tartary Buckwheat Based on High-throughput Sequencing Technology. Biotechnol Bull. 2016;7:7.

30. Yao H, Li C, Zhao H, Zhao J, Chen H, Bu T, Anhu W, Wu Q. Deep sequencing of the transcriptome reveals distinct flavonoid metabolism features of black tartary buckwheat (Fagopyrum tataricum Garetn.). Prog Biophys Mol Biol. 2017;124:49-60. https://doi.org/10.1016/j.pbiomolbio.2016. 11.003.

31. Di Toppi LS, Gabbrielli R. Response to cadmium in higher plants. Environ Exp Bot. 1999;41(2):105-30. https://doi.org/10.1016/s0098-8472(98)00058-6.

32. Allan DL, Jarrell WM. Proton and copper adsorption to maize and soybean root cell walls. Plant Physiol. 1989;89(3):823-832.10.2307/4271921.
33. Peng $\mathrm{H}-\mathrm{Y}$, Yang $\mathrm{X}-\mathrm{E}$, Tian S-K. Accumulation and ultrastructural distribution of copper in Elsholtzia splendens. J Zhejiang Univ Sci B. 2005;6(5):311. https://doi.org/10.1631/jzus.2005.B0311.

34. Wierzbicka M. Lead in the apoplast of Allium cepa L. root tips ultrastructural studies. Plant Sci. 1998;133(1):105-19. https://doi.org/10.1016/ S0168-9452(98)00023-5.

35. Zheng L, Peer T, Seybold V, Lütz-Meindl U. Pb-induced ultrastructural alterations and subcellular localization of $\mathrm{Pb}$ in two species of Lespedeza by TEM-coupled electron energy loss spectroscopy. Environ Exp Bot. 2012;77: 196-206. https://doi.org/10.1016/j.envexpbot.2011.11.018.

36. Maine MA, Duarte MV, Sune NL. Cadmium uptake by floating macrophytes. Water Res. 2001;35(11):2629-34. https://doi.org/10.1016/500431354(00)00557-1.

37. Ovecka M, Takac T. Managing heavy metal toxicity stress in plants: Biological and biotechnological tools. Biotechnol Adv. 2014;32(1):73-86. https://doi. org/10.1016/j.biotechadv.2013.11.011.

38. Luo Z-B, He J, Polle A, Rennenberg H. Heavy metal accumulation and signal transduction in herbaceous and woody plants: paving the way for enhancing phytoremediation efficiency. Biotechnol Adv. 2016;34(6):1131-48. https://doi.org/10.1016/j.biotechadv.2016.07.003.

39. Vinocur B, Altman A. Recent advances in engineering plant tolerance to abiotic stress: achievements and limitations. Curr Opin Biotechnol. 2005; 16(2):123-32. https://doi.org/10.1016/j.copbio.2005.02.001.

40. Shinozaki K, Yamaguchi-Shinozaki K. Molecular responses to dehydration and low temperature: differences and cross-talk between two stress signaling pathways. Curr Opin Plant Biol. 2000;3(3):217-23. https://doi.org/ 10.1016/S1369-5266(00)80068-0.

41. Pinho S, Ladeiro B. Phytotoxicity by Lead as Heavy Metal Focus on Oxidative Stress. J Bot. 2012;2012:1-10. https://doi.org/10.1155/2012/369572

42. Pourrut B, Jean S, Silvestre J, Pinelli E. Lead-induced DNA damage in Vicia faba root cells: potential involvement of oxidative stress. Mutat Res. 2011; 726(2):123-8. https://doi.org/10.1016/j.mrgentox.2011.09.001.

43. Clemens S. Toxic metal accumulation, responses to exposure and mechanisms of tolerance in plants. Biochimie. 2006;88(11):1707-19. https:// doi.org/10.1016/j.biochi.2006.07.003.

44. Singh R, Tripathi RD, Dwivedi S, Kumar A, Trivedi PK, Chakrabarty D. Lead bioaccumulation potential of an aquatic macrophyte Najas indica are related to antioxidant system. Bioresour Technol. 2010;101(9):3025-32. https://doi.org/10.1016/j.biortech.2009.12.031.

45. Gupta DK, Nicoloso FT, Schetinger MR, Rossato LV, Huang HG, Srivastava S, Yang XE. Lead induced responses of Pfaffia glomerata, an economically important Brazilian medicinal plant, under in vitro culture conditions. Bull Environ Contam Toxicol. 2011;86(3):272-7. https://doi.org/10.1007/s00128011-0226-y.

46. Wang $\mathrm{P}$, Zhang $\mathrm{S}$, Wang $\mathrm{C}$, Lu J. Effects of Pb on the oxidative stress and antioxidant response in a $\mathrm{Pb}$ bioaccumulator plant Vallisneria natans. Ecotoxicol Environ Saf. 2012;78(2):28-34. https://doi.org/10.1016/.ecoenv. 2011.11.008

47. Bazzaz FA, Carlson RW, Rolfe GL. Inhibition of Corn and Sunflower Photosynthesis by Lead. Physiol Plant. 1975;34(4):326-9. https://doi.org/10. 1111/j.1399-3054.1975.tb03847.x.

48. Poskuta JW, Parys E, Romanowska E, Gajdzis-Gujdan H, Wróblewska B: The effects of lead on photosynthesis, 14C distribution among photoassimilates and transpiration of maize seedlings. Acta Soc Bot Pol 1988, 57(1):149-155. https://doi.org/10.5586/asbp.1988.014

49. Chen Q, Zhang X, Liu Y, Wei J, Shen W, Shen Z, Cui J. Hemin-mediated alleviation of zinc, lead and chromium toxicity is associated with elevated photosynthesis, antioxidative capacity; suppressed metal uptake and oxidative stress in rice seedlings. Plant Growth Regul. 2016;81(2):1-12. https://doi.org/10.1007/s10725-016-0202-y.

50. Kumar A, Prasad MNV. Lead-induced toxicity and interference in chlorophyll fluorescence in Talinum triangulare grown hydroponically. Photosynthetica. 2015;53(1):66-71. https://doi.org/10.1007/s11099-015-0091-8.

51. Bassi R, Høyer-Hansen G, Barbato R, Giacometti G, Simpson D. Chlorophyllproteins of the photosystem II antenna system. J Biol Chem. 1987;262(27): 13333-41. https://doi.org/10.0000/PMID3308877.

52. Kohli SK, Handa N, Sharma A, Gautam V, Arora S, Bhardwaj R, Alyemeni MN, Wijaya L, Ahmad P. Combined effect of 24-epibrassinolide and salicylic acid mitigates lead $(\mathrm{Pb})$ toxicity by modulating various metabolites in Brassica juncea L. seedlings. Protoplasma. 2018;255(1):11-24. https://doi.org/10.1007/ s00709-017-1124-X. 
53. Dai LP, Xiong ZT, Huang Y, Li MJ. Cadmium-induced changes in pigments, total phenolics, and phenylalanine ammonia-lyase activity in fronds of Azolla imbricata. Environ Toxicol. 2006;21 (5):505-12. https://doi.org/10.1002/tox.20212.

54. Agati G, Azzarello E, Pollastri S, Tattini M. Flavonoids as antioxidants in plants: location and functional significance. Plant Sci. 2012;196:67-76. https://doi.org/10.1016/.jplantsci.2012.07.014.

55. Castañeda-Ovando A, MdL P-H, Páez-Hernández ME, Rodríguez JA, GalánVidal CA. Chemical studies of anthocyanins: A review. Food Chem. 2009; 113(4):859-71. https://doi.org/10.1016/j.foodchem.2008.09.001.

56. Lin $Y-F$, Aarts MG. The molecular mechanism of zinc and cadmium stress response in plants. Cell Mol Life Sci. 2012;69(19):3187-206. https://doi.org/ 10.1007/s00018-012-1089-Z.

57. Yan Z, Tam NFY. Effects of lead stress on anti-oxidative enzymes and stressrelated hormones in seedlings of Excoecaria agallocha Linn. Plant Soil. 2013; 367(1-2):327-38. https://doi.org/10.1007/s11104-012-1467-1.

58. Agrawal GK, Tamogami S, Iwahashi H, Agrawal VP, Rakwal R. Transient regulation of jasmonic acid-inducible rice MAP kinase gene (OsBWMK1) by diverse biotic and abiotic stresses. Plant Physiol Biochem. 2003;41(4):355-61. https://doi.org/10.1016/s0981-9428(03)00030-5.

59. Smékalová V, Doskočilová A, Komis G, Šamaj J: Crosstalk between secondary messengers, hormones and MAPK modules during abiotic stress signalling in plants. Biotechnol Adv 2014, 32(1):2-11.https://doi.org/10.1016/j. biotechadv.2013.07.009

60. Yadav SK. Heavy metals toxicity in plants: An overview on the role of glutathione and phytochelatins in heavy metal stress tolerance of plants. $\mathrm{S}$ Afr J Bot. 2010;76(2):167-79. https://doi.org/10.1016/j.sajb.2009.10.007.

61. Maestri E, Marmiroli M, Visioli G, Marmiroli N: Metal tolerance and hyperaccumulation: Costs and trade-offs between traits and environment. Environ Exp Bot 2010, 68(1):1-13.https://doi.org/10.1016/j.envexpbot.2009.10.011

62. Jiang W, Liu D. Pb-induced cellular defense system in the root meristematic cells of Allium sativum L. BMC Plant Biol. 2010;10(1):1 -8.10.1186/1471-2229-10-40.

63. Cellier M, Prive G, Belouchi A, Kwan T, Rodrigues V, Chia W, Gros P. Nramp defines a family of membrane proteins. Proc Natl Acad Sci. 1995;92(22):10089-93.

64. Tiwari M, Sharma D, Dwivedi S, Singh M, Tripathi RD, Trivedi PK. Expression in Arabidopsis and cellular localization reveal involvement of rice NRAMP. OsNRAMP 1, in arsenic transport and tolerance. Plant Cell Environ. 2014; 37(1):140-52. https://doi.org/10.1111/pce.12138.

65. Garrick MD, Dolan KG, Horbinski C, Ghio AJ, Higgins D, Porubcin M, Moore EG, Hainsworth LN, Umbreit JN, Conrad ME. DMT1: a mammalian transporter for multiple metals. BioMetals. 2003;16(1):41-54. https://doi.org/ 10.1023/a:1020702213099.

66. Arrivault $\mathrm{S}$, Senger $\mathrm{T}$, Kramer $\mathrm{U}$. The Arabidopsis metal tolerance protein AtMTP3 maintains metal homeostasis by mediating $\mathrm{Zn}$ exclusion from the shoot under Fe deficiency and Zn oversupply. Plant J. 2006;46(5):861-79. https://doi.org/10.1111/j.1365-313X.2006.02746.X.

67. Won-Yong S, Sohn EJ, Martinoia E, Lee YJ, Young-Yell Y, Jasinski M, Forestier C, Hwang I, Lee Y. Engineering tolerance and accumulation of lead and cadmium in transgenic plants. Nat Biotechnol. 2003;21(8):914-9. https://doi. org/10.1038/nbt850.

68. Hall JL, Williams LE. Transition metal transporters in plants. J Exp Bot. 2003; 54(393):2601-13. https://doi.org/10.1093/jxb/erg303.

69. Wierzbicka M. Lead in the apoplast of Allium cepa L. root tips—ultrastructural studies. Plant Sci. 1998;133(1):105-19. https://doi.org/10. 1016/s0168-9452(98)00023-5.

70. Grabherr MG, Haas BJ, Yassour M, Levin JZ, Thompson DA, Amit I, Adiconis $X$, Fan L, Raychowdhury R, Zeng QD, et al. Full-length transcriptome assembly from RNA-Seq data without a reference genome. Nat Biotechnol. 2011;29(7):644-U130. https://doi.org/10.1038/nbt.1883.

71. Camacho C, Coulouris G, Avagyan V, Ma N, Papadopoulos J, Bealer K, Madden TL. BLAST+: architecture and applications. BMC Bioinformatics. 2009;10(1):421.10.1186/1471 -2105-10-421.

72. Langmead B, Salzberg SL. Fast gapped-read alignment with Bowtie 2. Nat Methods. 2012;9(4):357. https://doi.org/10.1038/nmeth.1923.

73. Demidenko NV, Logacheva MD, Penin AA. Selection and validation of reference genes for quantitative real-time PCR in buckwheat (Fagopyrum esculentum) based on transcriptome sequence data. PLoS One. 2011;6(5): e19434. https://doi.org/10.1371/journal.pone.0019434.

\section{Publisher's Note}

Springer Nature remains neutral with regard to jurisdictional claims in published maps and institutional affiliations.

\section{Ready to submit your research? Choose BMC and benefit from}

- fast, convenient online submission

- thorough peer review by experienced researchers in your field

- rapid publication on acceptance

- support for research data, including large and complex data types

- gold Open Access which fosters wider collaboration and increased citations

- maximum visibility for your research: over $100 \mathrm{M}$ website views per year

At BMC, research is always in progress.

Learn more biomedcentral.com/submissions 